\title{
ANALISIS PONDASI TIANG PANCANG BREASTING DOLPHIN DAN MOORING DOLPHIN PADA DERMAGA TYPE JETTY
}

\author{
${ }^{1}$ Wiratna Tri Nugraha,${ }^{2}$ Yanda Pranoto \\ Program Studi Teknik Sipil Fakultas Teknik Universitas Suryakancana \\ wiratnayk@yahoo.com
}

\begin{abstract}
Abstrak
Pelabuhan adalah daerah perairan yang terlindung terhadap gelombang, yang dilengkapi dengan fasilitas laut dan juga fasilitas darat, diantaranya dermaga.

Bangunan dermaga terdiri dari beberapa bagian, diantaranya yaitu catwalk, fender, bollard, platform dan juga dolphin.Dolphin merupakan kontruksi utama dari dermaga.Dolphin adalah konstruksi yang digunakan untuk menahan benturan dan menambatkan kapal.Dolphin dapat dibedakan menjadi dua macam, yaitu dolphin penahan (breasting dolphin) dan juga dolphin penambat (mooring dolphin).

Lokasi yang akan ditinjau yaitu dermaga dengan tipe jetty di daerah Tayan, Pontianak, Kalimantan barat. Pada dermaga tersebut kapal yang bersandar yaitu berkapasitas 5.000 DWT (Dead Weigh Tonase), sedangkan pada penelitian ini, akan direncanakan beban kapal yang bersandar yaitu 10.000 DWT. Dengan tujuan untuk mengetahui apakah dimensi dolphin penahan (breasting dolphin) dan dolphin penambat (mooring dolphin) serta diameter pondasi dan jumlah pondasi tiang maupun kedalaman yang ada masih mampu untuk melayani beban kapal dengan kapasitas 10.000 DWT (Dead Weigh Tonase). Adapun hasil dari analisis yang telah dilakukan maka di dapatkan hasil sebagai berikut:

Kondisi eksisting di lapangan: kapal yang berlabuh berkapasitas 5.000 DWT, jumlah pondasi yang diperlukan yaitu 9 buah pondasi tiang pancang berdiameter $60 \mathrm{~cm}$, dengan kedalaman 18 meter, dimensi dolphin yang digunakan yaitu memiliki ukuran panjang 4,5 meter, lebar 4,5 meter dan tebal 1,5 meter.

Kondisi dari hasil penelitian: kapal yang berlabuh berkapasitas $10.000 \mathrm{DWT}$, jumlah pondasi yang diperlukan yaitu 12 buah pondasi tiang pancang berdiameter $60 \mathrm{~cm}$, dengan kedalaman 24 meter, dimensi dolphin yang digunakan yaitu memiliki ukuran panjang 6,6 meter, lebar 4,8 meter dan tebal 1,5 meter.
\end{abstract}

Kata kunci: pelabuhan, pondasi tiang pancang, dermaga, breasting dolphin dan mooring dolphin.

\section{PENDAHULUAN}

Dermaga merupakan salah satu bagian dari bangunan pelabuhan. Dermaga digunakan untuk merapat dan menambatkan kapal yang melakukan bongkar muat barang dan menaikturunkan penumpang. Bentuk serta dimensi atau ukuran dermaga tergantung dari jenis maupun ukuran kapal yang bertambat pada dermaga tersebut.

Bangunan dermaga terdiri dari beberapa bagian, diantaranya yaitu catwalk, fender, bollard, platform dan juga dolphin. Dolphin merupakan kontruksi utama dari dermaga. Dolphin adalah konstruksi yang digunakan untuk menahan benturan dan menambatkan kapal.Dolphin dapat dibedakan menjadi dua macam, yaitu dolphin penahan (breasting dolphin) dan juga dolphin penambat (mooring dolphin).Dolphin penahan mempunyai ukuran yang lebih besar dibandingkan dengan dolphin penambat, karena dolphin penahan direncanakan untuk menahan energi benturan kapal yang terjadi ketika
berlabuh.Menurut konstruksinya, dolphin dapat dibedakan menjadi dua, yaitu dolphin lentur dan dolphin kaku.Dolphin lentur dapat terdiri dari sekelompok tiang pancang pipa baja sedangkan dolphin kaku dapat terbuat dari tiang-tiang pancang beton.

Lokasi yang akan ditinjau yaitu dermaga dengan tipe jetty. Jetty yaitu dermaga yang dibangun menjorok cukup jauh ke arah laut, dengan maksud agar ujung dermaga berada pada kedalaman yang cukup untuk merapat kapal, sehingga kapal tidak kandas. Pada dermaga tersebut kapal yang bersandar yaitu berkapasitas 5.000 DWT, sedangkan pada penelitian ini, akan direncanakan beban kapal yang bersandar yaitu 10.000 DWT. Dengan tujuan untuk mengetahui apakah dimensi dolphin penahan (breasting dolphin) dan dolphin penambat (mooring dolphin) serta diameter pondasi dan jumlah pondasi tiang maupun kedalaman yang ada masih mampu untuk melayani beban kapal dengan kapasitas 10.000 DWT 


\section{TINJAUAN PUSTAKA}

A. Perhitungan Gaya yang Bekerja pada Dolphin

1. Untuk menghitung berat sendiri struktur dolphin yang ada, maka harus dihitung dulu volume beton bertulang pada dolphin tersebut, dengan rumus:

$\mathrm{V}=\mathrm{p} \times 1 \times \mathrm{t}$

Keterangan:

$\begin{array}{ll}\mathrm{V} & \text { : volume dolphin }\left(\mathrm{m}^{3}\right) \\ \mathrm{p} & \text { : panjang dolphin }(\mathrm{m}) \\ \mathrm{l} & \text { : lebar dolphin }(\mathrm{m}) \\ \mathrm{t} & \text { : tebal dolphin }(\mathrm{m}) \\ \text { Setelah } & \text { mengetahui volume }\end{array}$
tersebut, kemudian untuk mengetahui beratnya, volume tersebut dikalikan dengan berat jenis beton $\left(2400 \mathrm{~kg} / \mathrm{m}^{3}\right)$.

2. Gaya benturan kapal yang harus ditahan dermaga tergantung pada energi benturan yang diserap oleh sistem fender yang dipasang pada dermaga. Gaya benturan bekerja secara horisontal dan dapat dihitung berdasarkan energi benturan. Hubungan antara gaya dan energi benturan tergantung pada tipe fender yang digunakan. Besar energi benturan diberikan oleh rumus berikut ini:

$$
E=\frac{W \cdot V^{2}}{2 g} \cdot C \mathrm{~m} \cdot \mathrm{C \theta} \cdot \mathrm{Cs} \cdot \mathrm{Cc}
$$

Keterangan:

\begin{tabular}{|c|c|}
\hline$E$ & :energi benturan (ton-meter) \\
\hline$V$ & $\begin{array}{l}\text { :komponen tegak lurus sisi } \\
\text { dermaga dari kecepatan kapal } \\
\text { pada saat membentur dermaga } \\
(\mathrm{m} / \mathrm{d})\end{array}$ \\
\hline$W$ & :displacement (berat) kapal (ton) \\
\hline & : percepatan gravitasi $\left(\mathrm{m} / \mathrm{d}^{2}\right)$ \\
\hline & : koefisien massa \\
\hline & : koefisien eksentrisitas \\
\hline & : koefisien kekerasan 1 \\
\hline & : koefisien bentuk dari tambatan \\
\hline
\end{tabular}
perbandingan antara energi sisa dan energi kinetik kapal yang merapat, dan dapat dihitung dengan rumus berikut:

$$
C \theta=\frac{1}{1+(l / r)^{2}}
$$

\section{Keterangan:}

$L \quad$ :jarak sepanjang permukaan air dermaga dari pusat beratkapal sampai titik sandar kapal (seperti pada gambar 2.1) :jari-jari putaran di sekeliling pusat berat kapal padapermukaan air (seperti pada gambar 2.2)

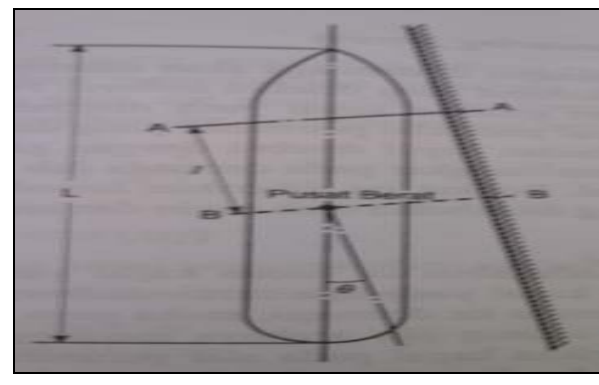

Gambar. 2.1. Jarak pusat berat kapal sampaititik sandar kapal

Sumber. Buku Perencanaan Pelabuhan (Bambang Triatmodjo)

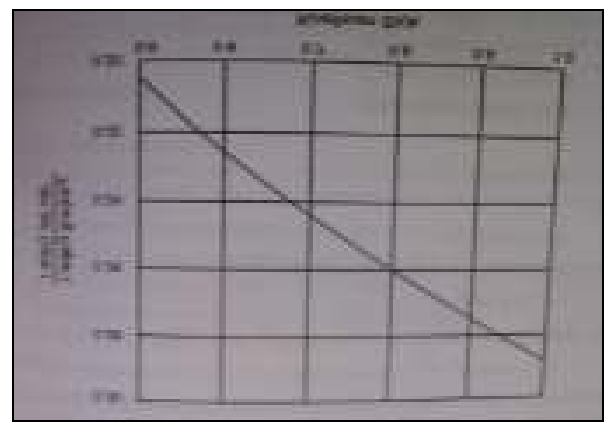

Gambar. 2.2. Jari-jari putaran di sekeliling pusat berat kapal

Sumber. Buku Perencanaan Pelabuhan (Bambang Triatmodjo)

3. Besar gaya angin tergantung pada arah dan kecepatan hembus angin yang dapat dihitung dengan rumus berikut ini:

Gaya longitudinal apabila angin datang dari arah haluan $\left(a=0^{\circ}\right)$

$$
R w=0,42 \cdot P a \cdot A w
$$

Gaya longitudinal apabila angin datang dari arah buritan $\left(a=180^{\circ}\right)$

$$
R w=0,5 \cdot P a \cdot A w
$$

Gaya lateral apabila angin datang dari arah lebar $\left(a=90^{\circ}\right)$

$R w=1,1, P a \cdot A w$

Keterangan:

$$
\begin{array}{ll}
R \mathrm{~W} & : \text { gaya akibat angin }(\mathrm{kg}) \\
\mathrm{Pa} & : \text { tekanan angin }\left(\mathrm{kg} / \mathrm{m}^{2}\right) \\
& =0,063 \cdot V^{2} \\
V & : \text { kecepatan angin }(\mathrm{m} / \mathrm{d}) \\
A \mathrm{w} & : \text { proyeksi bidang yang tertiup } \\
& \text { angin }\left(\mathrm{m}^{2}\right)
\end{array}
$$


Besar gaya yang ditimbulkan oleh gelombang diberikan oleh persamaan berikut ini:

$$
R a=C c \cdot \gamma w \cdot A c \cdot\left(\frac{V c^{2}}{2 \cdot g}\right)
$$

Keterangan:

$\begin{array}{ll}R a & : \text { gaya akibat gelombang }(\mathrm{kg}) \\ A \mathrm{c} & \text { :luas tampang kapal yang } \\ & \text { terendam air }\left(\mathrm{m}^{2}\right) \\ \Gamma \mathrm{W} & : \text { berat jenis air laut }\left(1025 \mathrm{~kg} / \mathrm{m}^{3}\right) \\ V \mathrm{c} & : \text { kecepatan gelombang }(\mathrm{m} / \mathrm{d}) \\ C \mathrm{c} & \text { :koefisien tekanan gelombang }\end{array}$

4. Wilayah gempa di Indonesia dibagi menjadi 6 zona berdasarkan percepatan puncak batuan dasarnya. Pembagian zona dapat dilihat pada gambar di bawah ini.

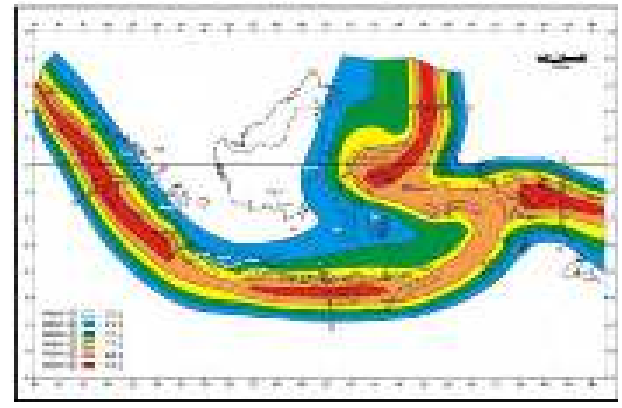

Gambar. 2.3. Wilayah gempa Indonesia dengan percepatan puncak batuan dasar dengan periode ulang 500 tahunSumber. SNI-1726-2002

Berdasarkan "SNI-1726-2002" gaya geser dasar nominal sebagai respons ragam yang pertama terhadap pengaruh gempa rencana, yaitu dapat dihitung dengan persamaan:

$$
V=\frac{\mathrm{C} . \mathrm{I}}{\mathrm{R}} \times W \mathrm{t}
$$

Keterangan:

$\mathrm{V} \quad$ : gaya geser nominal total (ton)

C : faktor respon gempa

faktor respon gempa tergantung pada periode getar alamistruktur, zona gempa dan jenis tanah.

B. Kapasitas daya dukung ijin tiang ditinjau berdasarkan kekuatan ijin tekan dan kekuatan ijin tarik, berikut penjelasan lebih lanjut tentang kapasitas daya dukung ijin tiang:

1. Daya dukung ijin tekan berdasarkan data sondir (Guy Sangrelat)

$$
\mathrm{Pa}=\frac{\mathrm{qc \times Ap}}{\mathrm{FK} 1}+\frac{\mathrm{Tf} \times \mathrm{Ast}}{\mathrm{FK} 2}
$$

Keterangan:

$\mathrm{Pa} \quad$ : daya dukung ijin tekan tiang

Qc : tahanan ujung konus sondir

Ap : luas penampang tiang

Tf :total friksi/jumlah hambatanpelekat

Ast : keliling penampang tiang

FK1 \& 2 : faktor keamanan 1 yaitu 3 : faktor keamanan 2 yaitu 5

Daya dukung ijin tekan berdasarkan data N-SPT (Meyerhof)

$$
\mathrm{Pa}=\frac{\mathrm{qc} \times A \mathrm{p}}{\mathrm{FK} 1}+\frac{\Sigma \text { li fi } \times A \text { at }}{\mathrm{FK} 2}
$$

2. Analisis daya dukung ijin tarik pondasi tiang terhadap kekuatan tanah, diantaranya dapat mempergunakan data berdasarkan data sondir (Guy Sangrelat) dan berdasarkan data N-SPT (Meyerhof), dari kedua metode tersebut, diambil daya dukung ijin tarik pondasi yang terkecil.

Daya dukung ijin tarik berdasarkan data sondir (Guy Sangrelat)

$$
\mathrm{P}_{\mathrm{ta}}=\frac{(\operatorname{Tf} \times \mathrm{Ast}) \times 0,70}{\mathrm{FK} 2}+\mathrm{Wp}
$$

Daya dukung ijin tarik berdasarkan data N-SPT (Meyerhof)

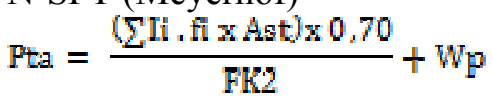

C. Perhitungan Jumlah Tiang serta Efisiensi Kelompok Tiang

1. Jumlah tiang yang diperlukan dihitung dengan membagi gaya aksial yang terjadi dengan daya dukung tiang. Rumus yang digunakan yaitu:

2. Untuk perhitungan efisiensi kelompok tiang berdasarkan rumus ConverseLabbarre dari Uniform Building Code AASHTO yaitu:

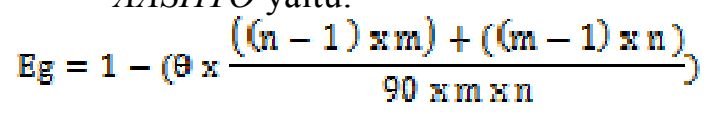

D. Beban Maksimum Tiang pada Kelompok Tiang.

Beban aksial dan momen yang bekerja akan didistrubusikan ke dolphin atau pile cap dan kelompok tiang berdasarkan rumus elastisitas dengan menganggap bahwa pile cap atau dolphin tersebut kaku sempurna, sehingga gaya-gaya yang bekerja tidak menyebabkan pile cap melengkung atau mengalami deformasi. Berikut rumus yang digunakan 
untuk menghitung beban maksimum pada tiang.

$$
P \operatorname{maks}=\frac{P u}{n p} \pm \frac{M y \cdot X \max }{n y \cdot \Sigma X^{2}} \pm \frac{M x \cdot Y \max }{n x \cdot \Sigma Y^{2}}
$$

E. Perhitungan Kapasitas Daya Dukung Ijin Horisontal Tiang.

Dalam analisis gaya horisontal, tiang perlu dibedakan menurut model ikatannya dengan penutup tiang (pile cap), karena itu tiang dibedakan menjadi 2 tipe, yaitu:

1. Tiang ujung jepit (fixed end pile)

2. Tiang ujung bebas (free end pile)

McNulty (1956) mendefinisikan tiang ujung jepit sebagai tiang yang ujung atasnya terjepit (tertanam) pada pile cap paling sedikit sedalam $60 \mathrm{~cm}$. Dengan demikian untuk tiang yang bagian atasnya tidak terjepit kurang dari $60 \mathrm{~cm}$ termasuk tiang ujung bebas (free end pile).

Pada tiang dengan ujung terjepit untuk mendapatkan daya dukung horisontal tiang dapat menggunakan metode Broms:

Daya dukung horisontal:

$$
\mathrm{Hu}=9 \cdot \mathrm{Cu} \cdot \mathrm{D} \cdot\left(\mathrm{Lp}-\frac{3 \cdot \mathrm{D}}{2}\right)
$$

Mencari nilai momen maksimum:

$$
M \max =H u \cdot\left(\frac{L p}{2}+\frac{3 \cdot D}{2}\right)
$$

Keterangan:

$\mathrm{Cu} \quad$ : undrained strength

D : diameter tiang

Lp : panjang tiang

Jika M max $>$ My maka tiang termasuk dalam tiang panjang.

Untuk tiang panjang (Mmax $>$ My)

Hu dinyatakan oleh persamaan:

$$
H u=\frac{2 . M y}{\frac{3 . D}{2}+\frac{f}{2}}
$$

Dimana:

$$
\mathrm{f}=\frac{\mathrm{Hu}}{(9 \cdot \mathrm{Cu} \cdot \mathrm{D})}
$$

\section{METODOLOGI PENELITIAN}

Penelitian ini bermaksud untuk mengevaluasi gaya-gaya yang bekerja atau mempengaruhi bangunan breasting dolphin dan, mooring dolphin khususnya pada pondasi tiang pancang dan menganalisis kapasitas daya dukung ijin tiang pada setiap kedalaman, serta menentukan jumlah tiang yang diperlukan, berikut dengan efisiensi kelompok tiang tersebut.

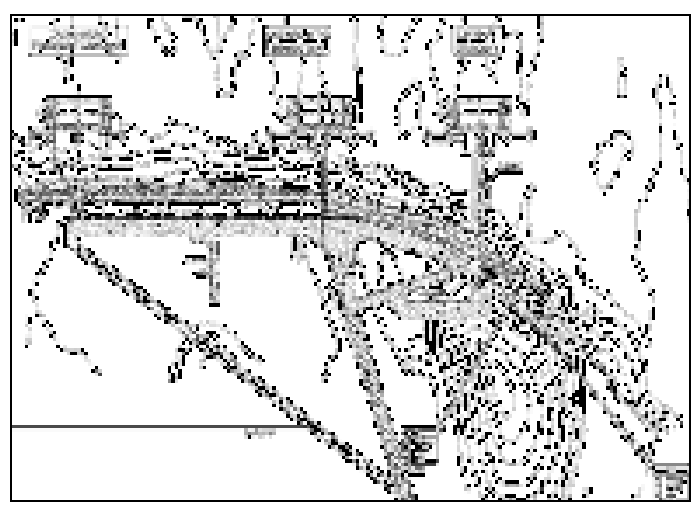

Gambar. 3.1. Layout jetty 1,2 dan 3 Sumber. PT. Panca Duta Prakarsa

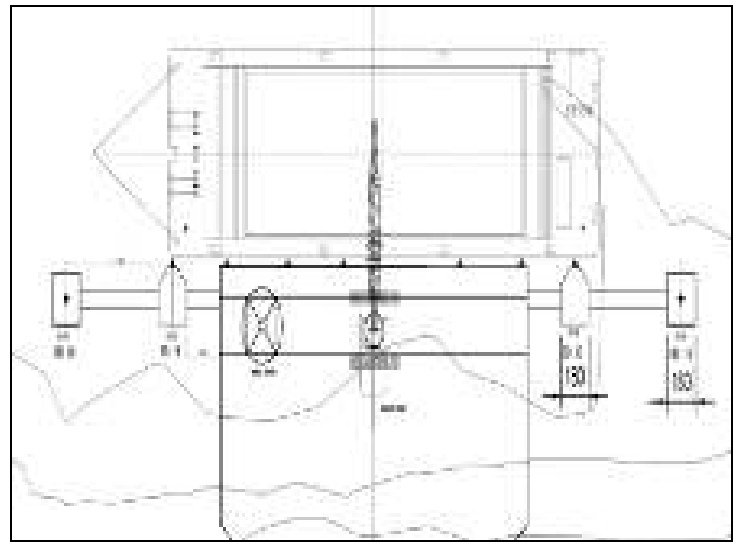

Gambar. 3.2. Dolphin penahan \& dolphin penambat jetty 1

Sumber. PT. Panca Duta Prakarsa

Pada bagian ini penulis akan membahas atau melakukan perhitungan yang sifatnya evaluasi dan menganalisis, pada 2 bangunan dermaga di jetty 1 yaitu dolphin penahan(breasting dolphin) dan dolphin penambat(mooring dolphin), analisa yang dilakukan diantaranya yaitu.

1. Evaluasi beban-beban pada struktur dolphin

2. Analisa daya dukung ijin vertikal tiang (tekan dan tarik)

3. Analisa jumlah tiang yang diperlukan dan efisiensi kelompok tiang

4. Analisa cek beban maksimum tiang pada kelompok tiang

Analisa daya dukung ijin horisontal tiang

\section{ANALISIS DATA}

a. Beban Berat Sendiri Struktur (D)

Terdiri dari breasthing dolphin dan mooring dolphin, dari masing-masing bagian dermaga tersebut, memiliki tebal serta luasan yang sama, berikut perhitungan berat sendiri struktur: 


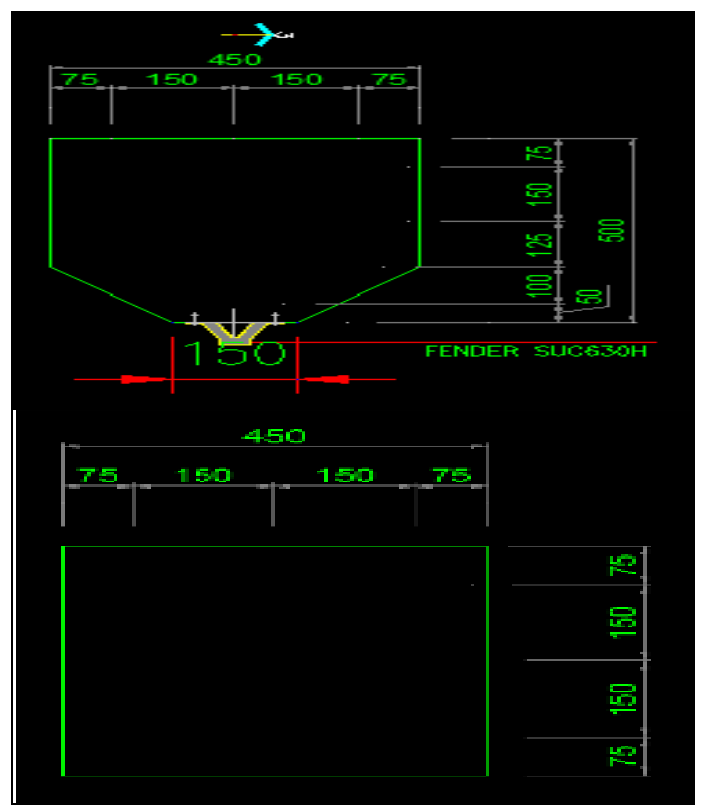

Gambar. 4.1. Tampak atas struktur breasting dolphin danmooring dolphin eksisting Sumber. PT. Panca Duta Prakarsa

$$
\begin{array}{ll}
\text { Tebal } & =1,5 \mathrm{~m} \\
\text { Luas } & =4,5 \mathrm{~m} \times 4,5 \mathrm{~m}=20,25 \mathrm{~m}^{2} \\
\text { Volume } & =\text { tebal x luas } \\
& =1,5 \mathrm{~m} \times 20,25 \mathrm{~m}^{2} \\
& =30,375 \mathrm{~m}^{3} \\
\text { Berat } & =2400 \mathrm{~kg} / \mathrm{m}^{3} \times 30,375 \mathrm{~m}^{3} \\
& =72.900 \mathrm{~kg} \\
& =72,9 \text { ton (berat dolphin) }
\end{array}
$$

\section{b. Gaya Sandar (Berthing Forces) (B)}

Breasthing dolphin di Pelabuhan Tayan Pontianak berada di tengah Sungai Kapuas.Breasting dolphin tersebut digunakan untuk bertambat kapal dengan data sebagai berikut:

1. Bobot kapal pada saat kosong:

$$
\text { 10.000 DWT }
$$

2. Berat total kapal pada saat terisi:

$$
\text { 13.996 Ton }
$$

3. Panjang kapal: $137 \mathrm{~m}$

4. Lebar kapal: $19,9 \mathrm{~m}$

5. Draft kapal : 8,2 m

6. Kecepatan angin maksimum di lokasi pelabuhan : $25 \mathrm{~m} / \mathrm{d}$

7. Luas bidang kapal yang terkena angina : $856 \mathrm{~m}^{2}$

8. Luas bidang kapal yang terendam: $238,8 \mathrm{~m}^{2}$

9. Kecepatan arus di sekitar pelabuhan: 1,7 $\mathrm{m} / \mathrm{s}$

10.Kecepatan kapal pada saat merapat ke dermaga : $0,15 \mathrm{~m} / \mathrm{s}$
11.Sudut yang dihasilkan kapal pada saat merapat : 10 derajat

12.Berat jenis air laut di sekitar pelabuhan : $1,025 \mathrm{t} / \mathrm{m}^{3}$

\section{c. Gaya Tambat (Mooring Forces) (M)}

Kapal yang merapat di dermaga akan ditambatkan ke mooringdolphin dengan menggunakan tali ke alat penambat yang disebut bollard. Pengikatan ini dimaksudkan untuk menahan gerakan kapal yang disebabkan oleh angin dan gelombang. Gaya tarikan kapal pada alat penambat yang disebabkan oleh tiupan angin dan gelombang pada badan kapal disebut dengan gaya tambat (mooring forces). Bollard ditanam atau diangker pada mooring dolphin, dan harus mampu menahan gaya tarikan kapal. Berikut langkah-langkah untuk mencari besaran gaya tarikan kapal yang ditimbulkan atau dihasilkan oleh angin dan gelombang.

\section{d. Gaya Gempa (E)}

Berdasarkan pembagian wilayah zona gempa, maka Pontianak termasuk kedalam wilayah zona gempa 1.Nilai faktor respon gempa dapat ditentukan berdasarkan grafik di bawah ini.

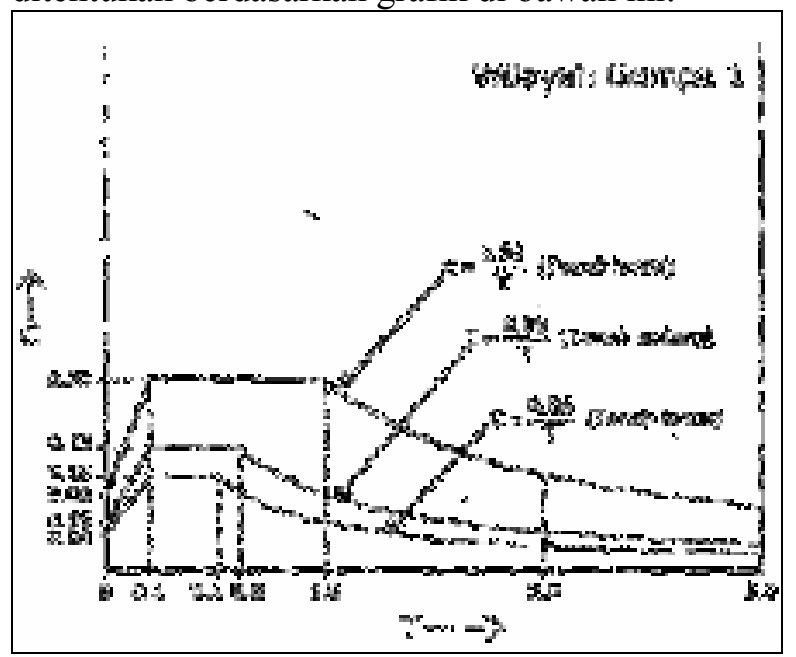

Gambar. 4.2. Respon spektrum gempa rencana untukwilayah gempa 1 Sumber. SNI-1726-2002

Dari pembacaan grafik di atas, dengan jenis tanah lunak (nilai hasil test penetrasi rata-rata yaitu 6,6), maka nilai $\mathrm{C}=0,20$ untuk struktur dolphin (breasting dolphin dan mooring dolphin). 


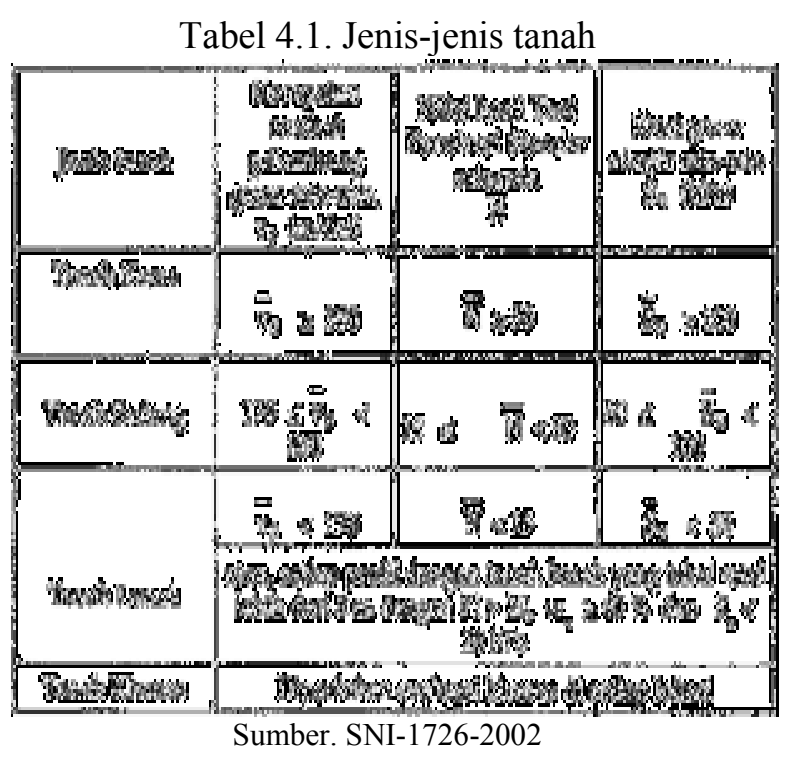

e. Gaya Arus Sungai A

1. Gaya horisontal (drag forces)

$$
\begin{aligned}
& \text { FD }=\frac{1}{2} \times C D \times p \circ \times A \cdot U^{2} \\
\text { FD }= & \frac{1}{2} \times 1 \times 1,025 \times(3,14 \times 0,6 \times 4,85) \times 1,7^{2} \\
\text { FD }= & \frac{1}{2} \times 1 \times 1,025 \times 9,1374 \times 1,7^{2} \\
\text { FD }= & 13,534 \text { ton } \\
\text { 2. Gaya vertikal (lift forces) } & \quad \text { FL }=\frac{1}{2} \times \mathrm{CL} \times \text { po } \times A \cdot \mathrm{U}^{2} \\
\text { FL }= & \frac{1}{2} \times 2 \times 1,025 \times(3,14 \times 0,6 \times 4,85) \times 1,7^{2} \\
\text { FL }= & \frac{1}{2} \times 2 \times 1,025 \times 9,1374 \times 1,7^{2} \\
\text { FL }= & 27,067 \text { ton }
\end{aligned}
$$

Sehingga gaya yang dihasilkan oleh arus sungai yaitu:

$F D+F L=13,534+27,067=40,601$ ton

\section{f. Kombinasi Pembebanan (Gaya Ultimit)}

Dari tiga kombinasi pembebanan, diambil kombinasi pembebanan atau gaya ultimit yang terbesar, yaitu 208,42 ton.

\section{g. Analisa Daya Dukung Ijin Vertikal Tiang}

Daya dukung ijin tiang ditinjau berdasarkan kekuatan ijin tekan dan kekuatan ijin tarik. Hal tersebut dipengaruhi oleh kondisi tanah di lokasi sekitar.

\section{Daya Dukung Ijin Tekan}

Analisis daya dukung ijin tekan pondasi tiang terhadap kekuatan tanah mempergunakan data berdasarkan data sondir (Guy Sangrelat), dan berdasarkan data N-SPT (Meyerhof). Dari kedua metode tersebut, diambil daya dukung ijin tekan pondasi yang terkecil yaitu berdasarkan data N-SPT, sebesar 27,8832 ton.

2. Daya Dukung Ijin Tarik

Berikut adalah hasil rekapitulasi daya dukung ijin tarik tiang dari 2 metode, pada kedalaman tanah 18 meter.

Tabel 4.1. Daya dukung ijin tarik tiang pada kedalaman 18 meter

\begin{tabular}{c|cc}
\hline NO & Metode & $\begin{array}{c}\text { Daya dukung ijin } \\
\text { tarik (ton) }\end{array}$ \\
\hline 1 & Sondir & 29,721984 \\
2 & SPT & 26,45136 \\
\hline
\end{tabular}

Dari kedua metode di atas, dipilih daya dukung ijin tarik tiang yang terkecil, yaitu hasil dari perhitungan daya dukung ijin tarik tiang berdasarkan data N-SPT, yaitu sebesar 26,45136 ton.

h. Analisa Jumlah Tiang dan Efisiensi Kelompok Tiang

1. Jumlah Tiang yang Diperlukan

Perhitungan jumlah tiang yang diperlukan pada suatu titik kolom menggunakan beban aksial dengan kombinasi beban (DL + LL) atau sering disebut beban terfaktor. Jumlah tiang yang diperlukan dihitung dengan membagi gaya aksial yang terjadi dengan daya dukung tiang Maka jumlah tiang yang dipakai yaitu sebanyak 9 tiang (jumlah pondasi tiang eksisting).

2. Efisiensi Kelompok Tiang

Daya dukung vertikal kelompok tiang harus lebih besar dari nilai gaya ultimit sebesar 208,42 ton.

Nilai daya dukung vertikal kelompok tiang lebih kecil dari gaya ultimit yang ada $(170,65$ ton $<208,42$ ton).....(Tidak OK).

Maka perlu ditambah jumlah tiang. Hal tersebut mengakibatkan perlu dilakukan pembesaran dimensi struktur dolphin, sehingga perlu dilakukan alternarif perencanaan dimensi struktur dolphin.

\section{i. Alternatif Perencanaan}

Berikut langkah-langkah perencanaan dimensi struktur dolphin serta penambahan jumlah tiang yang dibutuhkan agar nilai daya dukung vertikal kelompok tiang lebih besar dari gaya ulimit yang ada.

1. Berat sendiri struktur dolphin yang baru yaitu: 
Berikut gambar dimensi perencanaan struktur dolphin yang baru.

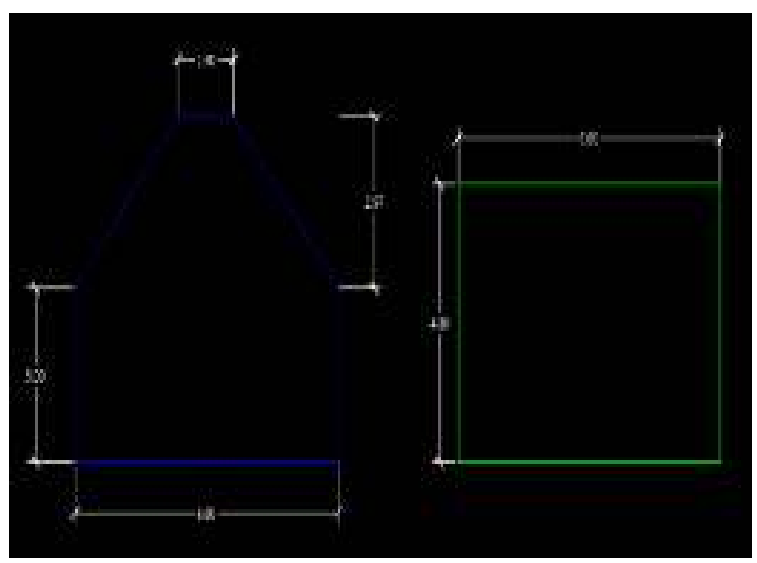

Gambar. 4.5. Tampak atas struktur breasting dolphin dan mooring dolphin yang baru

Dari ketiga kombinasi pembebanan, diambil kombinasi pembebanan atau gaya ultimit yang terbesar, yaitu 257,80ton.

2. Cek Tiang yang Dibutuhkan oleh Kelompok Tiang dan Efisiensi

Beban aksial P dari kombinasi pembebanan atau gaya ultimit diperoleh sebesar 257,80 ton.

Daya dukung ijin tekan tiang yaitu sebesar 27,8832 ton.Maka jumlah tiang vertikal yang digunakan yaitu sebanyak 12 tiang.

Berikut gambar breasting dolphin dan mooring dolphin hasil alternatif perencanaan.

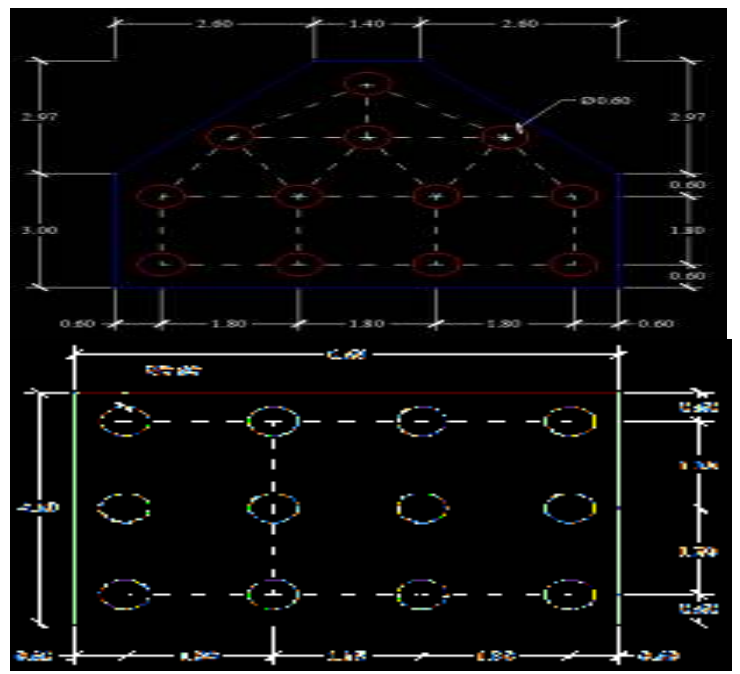

Gambar. 4.6. Jumlah tiang struktur breasting dolphin dan mooring dolphin yang baru

Daya dukung vertikal kelompok tiang dihitung oleh rumus berikut:
Eg $x$ jumlah pile $x$ daya dukung jijn tiang

(SPT

kedalaman $18 \mathrm{~m}$ )

$0,71 \times 12 \times 27,8832=237,56$ ton

Maka hasil daya dukung vertikal kelompok tiang lebih kecil dari gaya ultimit yang ada (237,56 ton $<257,80$ ton).....(Tidak OK)

3. Penambahan Kedalaman Tiang

Untuk mendapatkan nilai daya dukung vertikal kelompok tiang yang lebih besar atau sama dengan gaya ultimit yang ada, maka perlu ditambahkan kedalaman pondasi tiang agar daya dukung vertikal kelompok tiang meningkat.

Tiang eksisting dipancang pada kedalaman 18 $\mathrm{m}$, harus ditambah 6 meter, sehingga tiang yang dipancang mencapai kedalaman 24 meter.

Dari hasil data tanah sondir dan SPT diperoleh daya dukung ijin tiang pada kedalaman 24 meter Maka hasil daya dukung vertikal kelompok tiang lebih besar dari gaya ultimit yang ada, $(258,43$ ton $>257,80$ ton $) \ldots . .(\mathbf{O K})$

\section{j. Cek Beban Maksimum Tiang pada} Kelompok Tiang

Akibat beban-beban yang bekerja, serta dipengaruhi formasi atau susunan tiang dalam satu kelompok tiang, maka tiang-tiang tersebut akan mengalami gaya tekan atau tarik. Oleh karena itu tiang-tiang harus dikontrol untuk memastikan bahwa masingmasing tiang masih dapat menahan beban dari struktur atas sesuai dengan daya dukungnya. Bila Pmaks yang terjadi bernilai positif, maka pile mendapatkan gaya tekan.

Bila Pmaks yang terjadi bernilai negatif, maka pile mendapatkan gaya tarik.

Dari hasil tersebut dapat dilihat apakah masing-masing tiang masih memenuhi daya dukung tekan dan daya dukung tarik bila ada. Untuk menghitung beban maksimum pada kelompok tiang, harus memerlukan data sebagai berikut:

1. Gaya ultimit yang bekerja pada struktur dolphin. Gaya ultimit atau beban terfaktor yang bekerja pada struktur dolphin yang telah mengalami perencanaan ulang (pembesaran dimensi dolphin) yaitu sebesar 257,80 ton.

2. Jumlah tiang pada satu kelompok tiang yaitu 12 buah.

3. Momen yang bekerja pada struktur dolphin ada 2 arah, yaitu: 
a.Momen arah X, sebesar \pm 150 ton.m (Mx) (hasil interview)

b. Momen arah Y, sebesar \pm 75 ton.m (My)(hasil interview)

4. Daya dukung ijin tekan tiang yaitu sebesar 30,33240 ton

5. Daya dukung ijin tarik tiang 35,53224 ton

6. Gambar tampak atas struktur dolphin arah $\mathrm{X}$ dan $\mathrm{Y}$

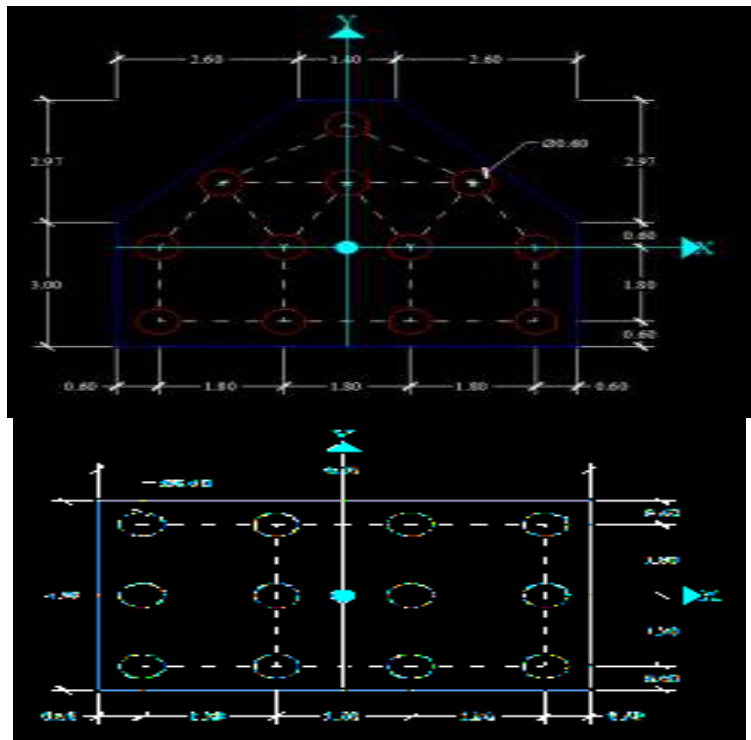

Gambar. 4.7. Titik berat serta sumbu arah X dan Ystruktur breasting dolphin dan mooring dolphin yang baru

\section{k. Analisa Daya Dukung Ijin Horisontal} Tiang

Dari kombinasi pembebanan, diambil kombinasi pembebanan atau gaya ultimit yang terbesar, yaitu $\mathrm{Fx}=120,94$ ton.

Sehingga gaya horisontal yang terjadi yaitu:

$$
\frac{\text { Fr (ton) }}{\text { 12tiang hna hy }}
$$

$\frac{120,94 \text { ton }}{12 \text { tiang (buah) }}=10,08$ ton $<H u=140,35$ ton

Dari hasil di atas, maka kondisi struktur untuk menahan gaya horisontal yang terjadi cukup kuat karena $\mathrm{Fx}<\mathrm{Hu}$, maka dapat dinyatakan aman.....(OK).

\section{KESIMPULAN}

\section{a. Kesimpulan}

Pada laporan tugas akhir dengan judul "Analisis Pondasi Tiang Pancang Breasting Dolphin dan Mooring Dolphin pada Dermaga
Type Jetty", dapat ditarik kesimpulan, diantaranya yaitu:

1. Gaya-gaya yang bekerja pada struktur dolphin (breasting dolphin dan mooring dolphin), seperti gaya-gaya di bawah ini, diantaranya yaitu:

a. Gaya yang timbul akibat berat sendiri struktur yaitu sebesar 72,9 ton (berat dolphin).

b. Gaya sandar (berthing forces) yang terjadi pada saat kapal akan merapat yaitu sebesar 12,60 ton.

c. Gaya tambat (mooring forces) yang dihasilkan akibat gaya angin dan gelombang, ketika kapal bertambat yaitu sebesar 47,586 ton.

d. Gaya yang dihasilkan pada saat terjadi gempa disekitar lokasi dolphin (breasting dan mooring dolphin) yaitu sebesar 3,68 ton.

e. Gaya yang ditimbulkan oleh arus sungai yaitu sebesar 40,601 ton.

f. Gaya terbesar yang dihasilkan dari kombinasi pembebanan yang ada yaitu sebesar 208,42 ton.

2. Kapasitas atau kekuatan daya dukung ijin vertikal dan horisontal tiang, dari data tanah yang ada (data sondir dan data SPT), yaitu:

a. Daya dukung ijin tekan pada kedalaman 18 meter yaitu:

\begin{tabular}{c|cc}
\hline NO & Metode & $\begin{array}{c}\text { Daya dukung ijin } \\
\text { tekan (ton) }\end{array}$ \\
\hline 1 & Sondir & 29,72952 \\
2 & SPT & 27,8832 \\
\hline
\end{tabular}

b. Daya dukung ijin tarik pada kedalaman 18 meter yaitu:

\begin{tabular}{c|cc}
\hline NO & Metode & $\begin{array}{c}\text { Daya dukung ijin } \\
\text { tarik(ton) }\end{array}$ \\
\hline 1 & Sondir & 29,721984 \\
2 & SPT & 26,45136 \\
\hline
\end{tabular}

\begin{tabular}{c|cccc}
\hline NO & Kondisi & \multicolumn{3}{c}{ Dimensi Struktur Dolphin } \\
\cline { 3 - 5 } & & $\begin{array}{c}\text { Panjang } \\
(\mathrm{m})\end{array}$ & $\begin{array}{c}\text { Lebar } \\
(\mathrm{m})\end{array}$ & $\begin{array}{c}\text { Tebal } \\
(\mathrm{m})\end{array}$ \\
& & 4,5 & 4,5 & 1,5 \\
2 & Eksisting & 6,6 & 4,8 & 1,5 \\
& Hasil & 6,6 & & \\
\hline
\end{tabular}


3. Jumlah tiang eksisting sebanyak 9 buah tiang tidak dapat mendukung gaya akibat tipe kapal yang lebih besar.

4. Perlu dilakukan alternatif perencanaan agar jumlah tiang yang diperlukan oleh dolphin dapat mencapai nilai efisiensi kelompok tiang akibat tipe kapal yang lebih besar, salah satunya yaitu melakukan pembesaran dimensi dolphin (breasting dolphin dan mooring dolphin). Berikut hasil perhitungan dimensidolphin yang diperlukan:

5. Setelah ukuran dolphin diperbesar, tetap saja dolphin tidak mampu menahan beban kapal yang lebih besar (10.000 DWT) sehingga tiang yang dibutuhkan yaitu sebanyak 12 buah tiang, dengan kedalaman tiang pancang semula 18 meter menjadi 24 meter. Sehingga daya dukung ijin vertikal tiang yang dipakai berdasarkan data tanah dari hasil sondir sebesar 30,33240 ton.

\section{DAFTAR PUSTAKA}

Christady Hardiyatmo Hary. 2011. Analisis dan Perancangan Fondasi II. Penerbit Gadjah Mada University Press. Yogyakarta.

Pamungkas Anugrah dan Harianti Erny.2013. Desain Pondasi Tahan Gempa Sesuai SNI 03-1726-2002 dan SNI 03-28472002.Penerbit Andi Offset.Yogyakarta.

SKBI-1.3.53.1987. Pedoman Perencanaan Pembebanan Untuk Rumah dan Gedung.

SNI 03-1726-2002. Tata Cara Perencanaan Ketahanan Gempa Untuk Bangunan Gedung.

Triatmodjo Bambang. 2009. Perencanaan Pelabuhan. Penerbit Beta Offset. Yogyakarta.

Kramadibrata Soedjono. 2002. Perencanaan Pelabuhan. Penerbit ITB. Bandung.

Ilham. 2014.Bahan Ajar Pelabuhan Rekayasa Transportasi II. Program Studi Teknik Sipil, Fakultas Teknik, Universitas Suryakancana.Cianjur.

Kartikasari Yualita. 2008. Desain Dermaga General Cargo dan Trestle Tipe Deck On Pile Di Pulau Kalukalukuang Provinsi Sulawesi Selatan. Program Studi Teknik Kelautan, Fakultas Teknik Sipil dan Lingkungan, ITB. Bandung. 